\title{
Characteristics of Disease Spectrum in relation to Species, Serogroups, and Adhesion Ability of Motile Aeromonads in Fish
}

\author{
Alicja Kozińska and Agnieszka Pẹkala \\ Department of Fish Diseases, National Veterinary Research Institute, Al. Partyzantów 57, 24-100 Puławy, Poland \\ Correspondence should be addressed to Alicja Kozińska, koala@piwet.pulawy.pl
}

Received 27 October 2011; Accepted 29 November 2011

Academic Editor: Andrej A. Romanovsky

Copyright ( 2012 A. Kozińska and A. Pękala. This is an open access article distributed under the Creative Commons Attribution License, which permits unrestricted use, distribution, and reproduction in any medium, provided the original work is properly cited.

\begin{abstract}
An attempt was made to delineate the relationship between of Aeromonas species and/or serogroups and specific disease symptoms in common carp Cyprinus carpio L. and rainbow trout Oncorhynchus mykiss Walbaum. The adhesion of Aeromonas strains to various tissues in relation to disease spectrum was also tested. All strains of A. hydrophila caused skin ulcers as well as septicaemia in both carp and trout while the other strains were able to cause only skin ulcers or some specific internal lesions with or without septicaemia depending on which species and/or serogroup they represented. Disease symptoms depended also on fish species. It was found that adhesion intensity of Aeromonas strains tested was significantly higher to tissues, which were susceptible to infection with these strains. The results indicate that adhesion to various cells of the fish organism is principal marker to detect virulent Aeromonas strains. The findings presented in this study may be helpful in the appraisal of aeromonads disease risk and kind of the infection in particular fish farms by epizootiological studies or/and during routine fish examinations. They will also be useful to improve and facilitate diagnosis of bacterial fish disease.
\end{abstract}

\section{Introduction}

The genus Aeromonas is composed of a large number of species. Currently, 17 genospecies and 14 phenospecies are recognized within this taxon [1]. Recently, seven newly described species have been proposed for inclusion to the genus Aeromonas [2]. The straight majority of species of the genus comprise motile and mesophilic strains and most of them are ubiquitous inhabitants of various aquatic ecosystems [3, 4]. Aeromonas salmonicida is only one species, which comprises nonmotile and psychrophilic strains. However, this species includes also motile strains referred to sometimes as A. hydrophila-like [1]. Motile and mesophilic Aeromonas spp. are well known as opportunistic but important pathogens of fish and other poikilothermic and homeothermic organisms including humans [2]. A. hydrophila and $A$. veronii bt. sobria are predominantly responsible for fish infections but $A$. caviae, A. jandaei, $A$. sobria, A. bestiarum, and mesophilic strains of $A$. salmonicida have also been reported as important pathogens of some fish species [5-8].
Mesophilic Aeromonas spp. show large serological diversity and include 96 established or provisional O-serogroups (SG) in NIH serotyping system (National Institute of Health, Japan) of Sakazaki and Shimada [9]. However, only some of them such as O3, O6, O11, O14, O16, O18, O21 O29 O33, and $\mathrm{O} 41$ seem to be associated with virulence for specific fish species [10-12].

Infections caused by mesophilic aeromonads in fish vary greatly in appearance. The pathological lesions may be only seen in the skin or internal organs but sometimes the lesions spread to other body sites causing systemic infection $[6$, 13-16]. It is commonly known that various stress factors and virulence level of Aeromonas strains have important influence on the disease severity. However, there are only partial data about the association of particular Aeromonas species and/or serogroups with disease spectrum in some fish species $[6,17,18]$.

In the present study, an attempt was made to delineate the relationship between Aeromonas species and serogroups dominant in Polish fish farms and specific disease symptoms in common carp Cyprinus carpio L. and rainbow trout 
Oncorhynchus mykiss Walbaum. Moreover, the adhesion of the selected Aeromonas strains to skin, internal organs, and blood cells of these fish species was tested to determine the importance of this property in disease spectrum.

\section{Material and Methods}

2.1. Fish. Healthy common carp and rainbow trout weighing 80 to $100 \mathrm{~g}$ were used for the challenge tests. Fish used for adhesion tests were sampled at the moment when they grew up to the weight of 400 to $600 \mathrm{~g}$. All fish originated from the same carp or trout farms, which were aeromonadsdisease-free at least two years before the experiments. The fish were maintained in 3001 glass tanks with dechlorinated and aerated water before and during experiments. Water temperature was $20^{\circ} \mathrm{C} \pm 1^{\circ} \mathrm{C}$ for carp and $12^{\circ} \mathrm{C} \pm 1^{\circ} \mathrm{C}$ for trout. Fish were fed with pellets (Aller Aqua, Poland) suitable for the given fish species.

2.2. Bacterial Strains. Aeromonas strains were selected from those which have been previously identified to the species level, serogrouped, and classified as pathogenic for fish $[7,11]$. All these strains showed similar pathogenicity factors, such as haemolytic and proteolytic activity, measured quantitatively as previously described [7, 19]. The strains were stored in trypticase soy broth (TSB) supplemented with $20 \%$ of glycerol at $-80^{\circ} \mathrm{C}$. The day before use, they were recultured on TSB and incubated overnight at $27^{\circ} \mathrm{C}$.

2.3. Challenge. Fifty-one of Aeromonas strains were used for challenge. The strains represented the species $A$. hydrophila, A. bestiarum, A. salmonicida (mesophilic strains), A. sobria, and $A$. veronii bt. sobria, serogroups $\mathrm{O} 3, \mathrm{O} 6, \mathrm{O} 11, \mathrm{O} 16$, $\mathrm{O} 18, \mathrm{O} 21, \mathrm{O} 29, \mathrm{O} 33, \mathrm{O} 41$, and six provisional groups $\mathrm{O}$ (PGO) (Table 1). The $24 \mathrm{~h}$ bacterial cultures in TSB were diluted in sterile phosphate buffered saline (PBS) to the final concentration of $5 \times 10^{6}$ bacterial cells $\mathrm{mL}^{-1}$. Before infection, fish were anaesthetized by bath for $2-5 \mathrm{~min}$. in solution of MS-222 (Sigma), at the concentration from 75 to $150 \mu \mathrm{g} \mathrm{L}^{-1}$ of water (lower doses for trouts and higher for carps). For each strain, five carps and five trouts were injected subcutaneously (Sc) with $0.1 \mathrm{~mL}$ of the diluted bacterial culture. The same numbers of other individuals were injected intraperitoneally (Ip) with $0.5 \mathrm{~mL}$ of the same inoculum. Symptoms of the disease were recorded daily during two weeks. The fish being in death throes or freshly dead were used for clinical, postmortem, and bacteriological examinations. Skin, liver, kidney, and blood samples were taken for bacteriological tests.

Local Ethic Commission in Lublin approved the procedure concerning experiments on fish.

2.4. Adhesion to Skin, Internal Organs, and Blood Cells. Selected 20 Aeromonas strains causing different disease symptoms were used for these tests (see Table 4 ). The strains were grown overnight in TSB at $27^{\circ} \mathrm{C} \pm 1^{\circ} \mathrm{C}$ and centrifuged at $3,000 \mathrm{~g}$ for $10 \mathrm{~min}$, and the bacterial pellets
TABLE 1: Aeromonas strains used for challenge tests.

\begin{tabular}{|c|c|c|}
\hline Aeromonas species & Strains & Serogroup \\
\hline \multirow{4}{*}{ A. hydrophila } & Pt39, Pt40 & $\mathrm{O} 11$ \\
\hline & Pt104, Pt109 & O16 \\
\hline & W58 & PGO10 \\
\hline & W68 & PGO11 \\
\hline \multirow{9}{*}{ A. bestiarum } & J4N, K15S & $\mathrm{O} 3$ \\
\hline & K167, K206 & $\mathrm{O} 11$ \\
\hline & P1W, K2 & $\mathrm{O} 16$ \\
\hline & K14S, K296 & $\mathrm{O} 18$ \\
\hline & K190, Pt303 & $\mathrm{O} 33$ \\
\hline & K301, K333 & PGO1 \\
\hline & Pt16 & PGO2 \\
\hline & K339 & PGO4 \\
\hline & $\mathrm{P} 1 \mathrm{~S}$ & PGO6 \\
\hline \multirow{8}{*}{ A. salmonicida } & K401, K402 & O3 \\
\hline & W32 & $\mathrm{O} 11$ \\
\hline & K299, K299B & $\mathrm{O} 16$ \\
\hline & K352A, K352C & $\mathrm{O} 33$ \\
\hline & A16 & $\mathrm{O} 18$ \\
\hline & $1 S 91$ & PGO1 \\
\hline & $\mathrm{A} 11, \mathrm{~A} 17$ & PGO2 \\
\hline & 1S95, K116 & PGO6 \\
\hline \multirow{3}{*}{ A. sobria } & $\mathrm{K} 24, \mathrm{~K} 24 \mathrm{C}$ & $\mathrm{O} 3$ \\
\hline & K150, K354 & $\mathrm{O} 16$ \\
\hline & K311 & PGO1 \\
\hline \multirow{6}{*}{ A. veronii bt. sobria } & S4W, K48, K348 & O6 \\
\hline & K144, Pt57 & $\mathrm{O} 11$ \\
\hline & K151, K202 & $\mathrm{O} 33$ \\
\hline & W62, K166, K170 & O41 \\
\hline & K156 & PGO2 \\
\hline & K168 & PGO4 \\
\hline
\end{tabular}

were suspended in PBS to final concentration of $10^{7}$ cells $\mathrm{mL}^{-1}$. Fish were killed by bath in the suspension of MS222 at the lethal concentration for $10-15 \mathrm{~min}$. Then they were washed under tap water and disinfected in 70\% ethanol. One square centimeter of carp and trout skin (CS and TS, resp.), and $0.5 \mathrm{~g}$ of carp kidney (CK) and trout liver (TL) were taken. The samples were placed in separate Petri dishes containing $30 \mathrm{~mL}$ of particular strain suspensions and incubated for $1 \mathrm{~h}$ at room temperature with continuous gentle shaking. Then, the samples were carefully washed by dipping five times in containers with sterile PBS and finally under stream of the saline. After homogenization, several tenfold dilutions were performed and $100 \mu \mathrm{L}$ of the material from each dilution was inoculated onto blood agar (BA) and incubated for $48 \mathrm{~h}$ at $27^{\circ} \mathrm{C} \pm 1^{\circ} \mathrm{C}$. Colonies were counted, and, after considering the dilution, the number of colonyforming units (cfus) was determined. The samples of CS, TS, 


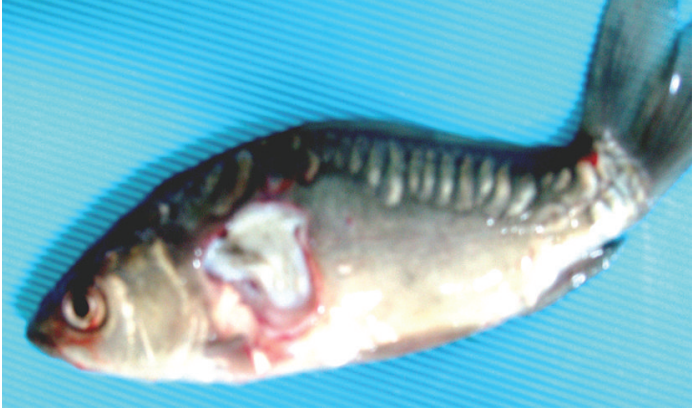

(a)

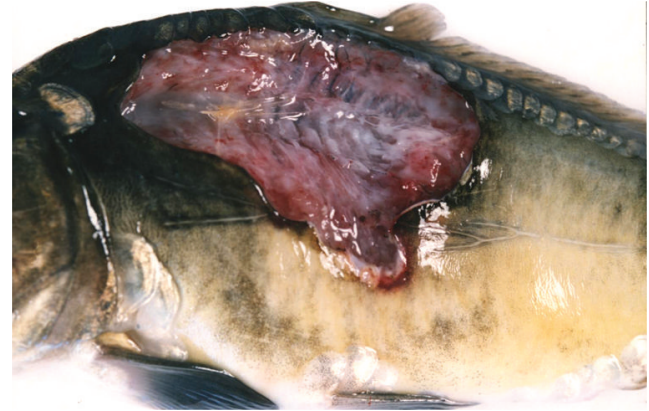

(b)

Figure 1: Ulcers in carps Sc challenged with A. hydrophila strain Pt39 (a) and A. bestiarum strain J4N (b). Very deep ulcer exposing skeleton after injection of A. bestiarum.

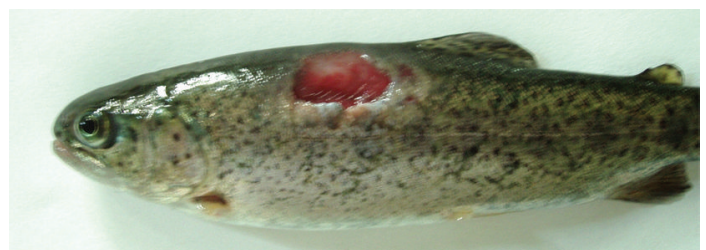

FIGURE 2: Skin ulcer penetrating deep into the muscle in trout Sc challenged with A. hydrophila Pt104.

CK, and TL exposed to sterile PBS were used as controls. For photographic documentation, adhesion was also tested on microscopic slides. After washing and disinfection of fish, surface mucous with epidermis, CK and TL were taken separately, diluted in sterile PBS in the ratio of $1: 2$ and homogenized. Additionally, carp and trout blood was also used. One hundred microliters of mucous, CK and TL homogenates and three drops of blood were smeared onto slides, air-dried, and fixed for $10 \mathrm{~min}$ with methanol. Then, the slides were incubated as described above and washed under quite strong stream of sterile PBS. The slides were stained by the Gram method and examined under a light microscope. Controls were incubated in sterile PBS. The photographs were made by camera connected with the microscope.

2.5. Statistical Analysis. Adhesion intensity (number of cfus) of two groups of Aeromonas strains was compared. The first one contains all strains signed as "+" and the second one contains all strains signed as "-" (see Table 5). At first, F-Seconder's test was used to check if variances of the two groups are statistically consistent and then U-MannWhitney-Wilcoxon's test was used to compare means of the data of the two groups at $\alpha \leq 0.05$.

\section{Results}

3.1. Disease Symptoms after Challenge in relation to Aeromonas Species and Serogroups. The ability of particular Aeromonas strains to cause specific disease symptoms after challenge of carp and trout are presented in Tables 2 and 3, respectively, and in Figures 1, 2, 3, and 4.
All strains except one of $A$. veronii bt. sobria (serogroup O41) caused external lesions on the body surface in carps after Sc challenge. Skin ulcers penetrating into subcutaneous muscle were usually formed (Figure 1). Skin ulcers in trout were formed only after Sc injection with all strains of $A$. hydrophila (Figure 2) and $A$. veronii bt. sobria except one belonging to serogroup O41. Similar lesions in trout were also caused by $A$. bestiarum SGs O16, PGO2, and PGO6 and A. salmonicida SG $\mathrm{O} 3$ strains. A. veronii bt. sobria strains belonging to serogroups $\mathrm{O} 6$ and $\mathrm{O} 11$ caused especially extensive dermatitis in carp (Figure 3) and symptoms of septicaemia such as distended anus abdomen swelling, exophthalmia, ascitic fluid in peritoneal cavity, anaemia or haemorrhages in internal organs, kidney watery, and jellylike discharge in the intestine were observed. All fish died within 2-4 days after challenge. The remaining strains did not cause lesions in internal organs after Sc challenge.

Ip challenge with each strain of $A$. hydrophila resulted in septicaemia in both carp and trout with the symptoms described above. Similar symptoms were caused by all strains of $A$. veronii bt. sobria (Figure 4(a)) and $A$. salmonicida belonging to SG $\mathrm{O} 3$ in carp and by all strains of $A$. sobria and $A$. salmonicida (Figure 4(b)) except one strain (A16) of the later species in trout. The disease showed acute form and $60 \%$ to $100 \%$ of infected fish died during 4 to 7 days after challenge. The strains belonging to the remaining Aeromonas species or serogroups caused relatively mild lesions such as increased moistness, anaemia, sometimes haemorrhages in internal organs and enlargement spleen or did cause no disease symptom after Ip injection (Tables 2 and 3).

Bacteria used to challenge were reisolated in all cases from the affected tissues and also from blood when systemic infection observed.

3.2. Disease Symptoms in relation to Adhesion Ability. No bacteria were detected in the control samples of the skin and internal organs after incubation on either BA or coated slides (Figure 5). The cfu numbers from $5 \times 10^{2}$ to $6.8 \times 10^{7}$ were received from the samples exposed to particular Aeromonas strains (Table 4). All strains causing skin ulcers, dermatitis, or any lesions in internal organs in the given fish species showed strong adhesion to these tissues at mean number 
TABLE 2: Disease symptoms in challenged carp in relation to Aeromonas species and serogroups.

\begin{tabular}{|c|c|c|}
\hline Lesions after challenge & Species & Serogroups \\
\hline \multirow{3}{*}{ Only external (ulcers or dermatitis) } & A. bestiarum & O16, O18, O33, PGO1, PGO2, PGO4 \\
\hline & A. salmonicida & O11, O16, O33, O18, PGO1, PGO2, PGO6 \\
\hline & A. sobria & O3, O16, PGO1 \\
\hline Only internal & A. veronii bt. sobria** & O41 (strain W62) \\
\hline \multirow[t]{3}{*}{ Both external and internal } & A. hydrophila** & O11, O16, PGO10, PGO11 \\
\hline & A. bestiarum* & O3, O11, PGO6 \\
\hline & A. salmonicida** & $\mathrm{O} 3$ \\
\hline
\end{tabular}

A. veronii bt. sobria**

O6, O11, O33, O41 (strains K166, K170), PGO2, PGO4

${ }^{*}$ Increased moistness of internal organs, enlarged spleen, anaemia and/or haemorrhages in liver-pancreas; ${ }^{* *}$ systemic infection.

TABLE 3: Disease symptoms in challenged trout in relation to Aeromonas species and serogroups.

\begin{tabular}{lcc}
\hline Lesions after challenge & Aeromonas species & Aeromonas serogroups \\
\hline Only external (ulcers) & A. veronii bt. sobria & O. bestiarum* \\
Only internal & A. salmonicida** & O3, O11, O33, PGO1, PGO4 \\
& A. sobria** & O11, O16, O33, PGO1, PGO2, PGO6 \\
Both external and internal & A. hydrophila** & O3, O16, PGO1 \\
& A. bestiarum* & O11, O16, PGO10, PGO11 \\
& A. salmonicida** & O16, PGO2, PGO6 \\
A. veronii bt. sobria* & O11, O16, O33, PGO1, PGO2, PGO6 \\
\hline
\end{tabular}

${ }^{*}$ Increased moistness, anaemia and/or haemorrhages in internal organs, enlarged spleen; ${ }^{* *}$ systemic infection.

TABLE 4: The ability of Aeromonas strains to cause pathological lesions in carp and trout skin and internal organs in relation to their adhesion to these tissues.

\begin{tabular}{|c|c|c|c|c|c|c|c|c|}
\hline \multirow{2}{*}{ Strain } & \multicolumn{4}{|c|}{ Ability to cause lesions in tissues } & \multicolumn{4}{|c|}{ No. of bacterial cells adhered to tissues } \\
\hline & CS & $\mathrm{CIO}$ & TS & TIO & CS & CK & TS & $\mathrm{TL}$ \\
\hline Pt39 & + & + & + & + & $2.2 \times 10^{6}$ & $6 \times 10^{6}$ & $3.5 \times 10^{6}$ & $10^{7}$ \\
\hline Pt104 & + & + & + & + & $8.5 \times 10^{6}$ & $4.7 \times 10^{6}$ & $3.8 \times 10^{6}$ & $8 \times 10^{6}$ \\
\hline $\mathrm{J} 4 \mathrm{~N}$ & + & + & - & + & $3.6 \times 10^{6}$ & $5.9 \times 10^{6}$ & $5.5 \times 10^{2}$ & $4.5 \times 10^{6}$ \\
\hline K167 & + & + & - & + & $4 \times 10^{6}$ & $5 \times 10^{6}$ & $2 \times 10^{3}$ & $2.6 \times 10^{6}$ \\
\hline K206 & + & + & - & + & $5.2 \times 10^{6}$ & $8.2 \times 10^{6}$ & $10^{4}$ & $7 \times 10^{6}$ \\
\hline $\mathrm{K} 2$ & + & - & + & + & $6 \times 10^{6}$ & $4 \times 10^{3}$ & $5 \times 10^{6}$ & $6 \times 10^{6}$ \\
\hline P1W & + & - & + & + & $9.6 \times 10^{5}$ & $4.5 \times 10^{3}$ & $9.5 \times 10^{5}$ & $2.2 \times 10^{7}$ \\
\hline Pt303 & + & - & - & + & $10^{6}$ & $2 \times 10^{3}$ & $9 \times 10^{3}$ & $8.8 \times 10^{6}$ \\
\hline K402 & + & + & + & + & $2.6 \times 10^{6}$ & $2 \times 10^{6}$ & $4.8 \times 10^{6}$ & $10^{7}$ \\
\hline K299 & + & - & - & + & $3.6 \times 10^{6}$ & $6 \times 10^{4}$ & $1.3 \times 10^{4}$ & $2 \times 10^{7}$ \\
\hline A16 & + & - & - & - & $9.2 \times 10^{5}$ & $6 \times 10^{2}$ & $2 \times 10^{3}$ & $6 \times 10^{2}$ \\
\hline K352A & + & - & - & + & $2.9 \times 10^{6}$ & $2.7 \times 10^{4}$ & $5 \times 10^{2}$ & $3 \times 10^{7}$ \\
\hline K24 & + & - & - & + & $1.2 \times 10^{6}$ & $3 \times 10^{4}$ & $3.5 \times 10^{3}$ & $6.8 \times 10^{7}$ \\
\hline K354 & + & - & - & + & $9.5 \times 10^{5}$ & $8 \times 10^{2}$ & $6 \times 10^{2}$ & $7.3 \times 10^{6}$ \\
\hline K48 & + & + & + & - & $2 \times 10^{7}$ & $6 \times 10^{7}$ & $9 \times 10^{6}$ & $2.8 \times 10^{6}$ \\
\hline Pt57 & + & + & + & + & $2.9 \times 10^{7}$ & $5.3 \times 10^{7}$ & $6.8 \times 10^{6}$ & $6.5 \times 10^{6}$ \\
\hline K1170 & + & + & + & - & $4 \times 10^{6}$ & $6 \times 10^{6}$ & $8.5 \times 10^{6}$ & $2.4 \times 10^{4}$ \\
\hline W62 & - & + & - & - & $2.5 \times 10^{6}$ & $6 \times 10^{6}$ & $5 \times 10^{2}$ & $2 \times 10^{3}$ \\
\hline K166 & + & + & + & - & $9 \times 10^{6}$ & $9 \times 10^{6}$ & $6.6 \times 10^{6}$ & $4.2 \times 10^{3}$ \\
\hline K168 & + & + & + & - & $2.8 \times 10^{6}$ & $9.5 \times 10^{6}$ & $8.8 \times 10^{5}$ & $6.5 \times 10^{2}$ \\
\hline
\end{tabular}

CS and TS: carp and trout skin, respectively; CIO and TIO: carp and trout internal organs, respectively; CK: carp kidney; TL: trout liver. 


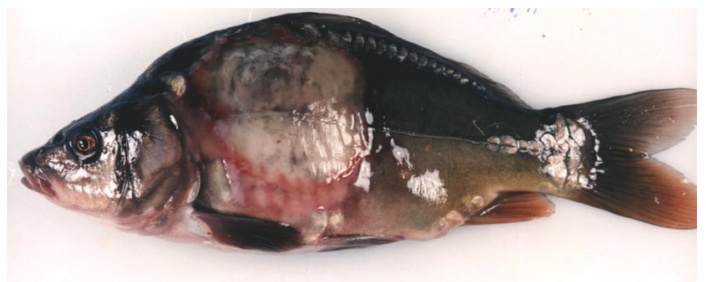

(a)

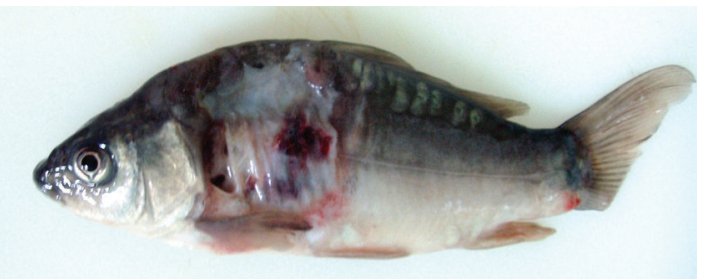

(b)

FIgURE 3: Extensive dermatitis in carp Sc challenged with A. veronii bt. sobria strains Pt 57 (a) and K48 (b). Distended anus (arrow) was the first symptom of septicaemia.

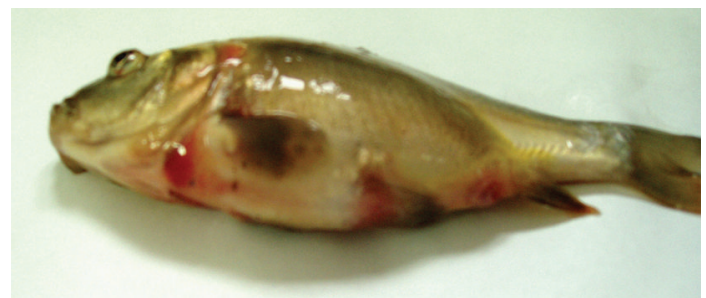

(a)

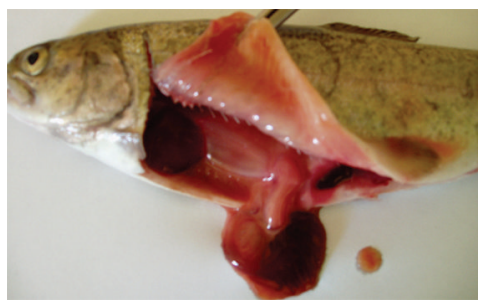

(b)

Figure 4: Septicaemia in fish Ip challenged with A. veronii bt. sobria strain K151 (a) and A. hydrophila strain Pt104 (b): exophthalmia, swelling of abdomen, and intensive congestions on the body surface in carp (a); enlarged spleen, intensive congestions, and liquefaction of internal organs in trout (b).

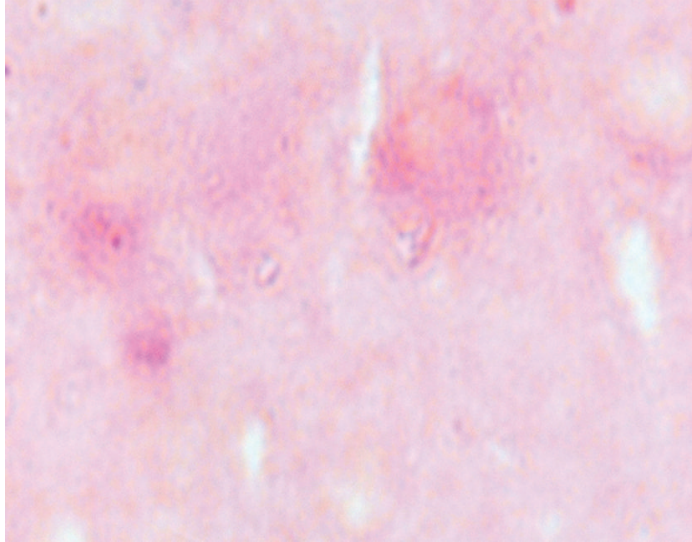

(a)

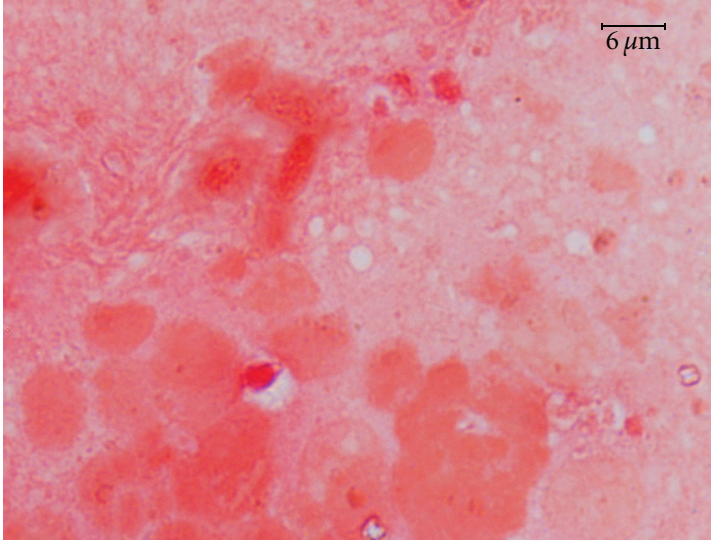

(b)

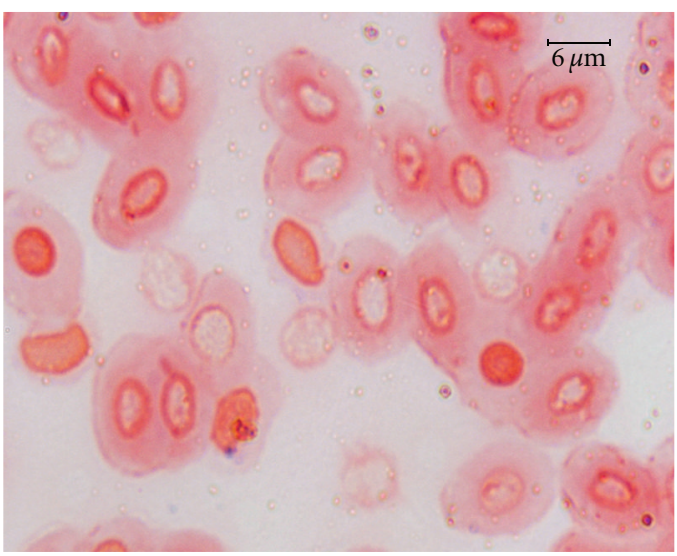

(c)

Figure 5: Control slides covered with homogenized carp skin mucus (a), trout liver (b), and carp blood (c): no bacterial cells are visible. 


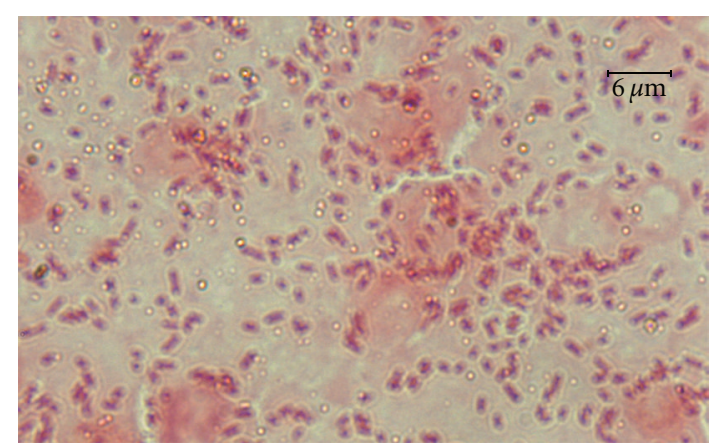

(a)

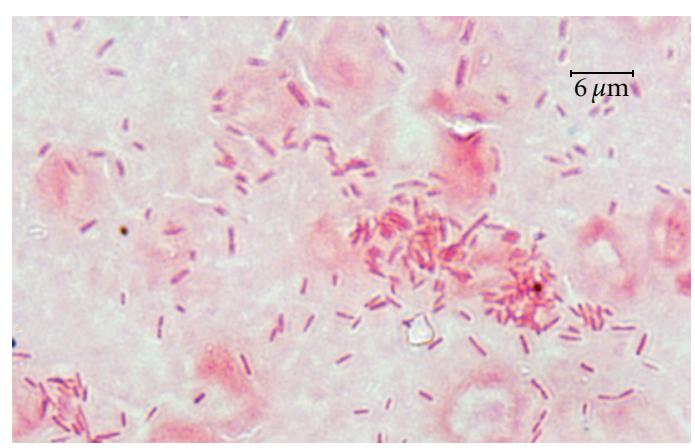

(b)

FIgURE 6: Numerous bacterial cells of A. veronii bt. sobria strain K48 adhering to carp mucus and epidermal cells (a) and carp kidney (b).

TABle 5: Adhesion intensity of groups of Aeromonas strains which were able $(+)$ or unable $(-)$ to cause skin ulcers or dermatitis (SU/D) or any lesions in internal organs (IOL) in both carp and trout.

\begin{tabular}{lcc}
\hline \multicolumn{1}{c}{ Aeromonas strains } & $\begin{array}{l}\text { Mean number of bacterial } \\
\text { cells adhered to skin and } \\
\text { internal organs }\end{array}$ \\
Group & Number & $5.2 \times 10^{6}$ \\
\hline SU/D+ & 29 & $2.3 \times 10^{5}\left(4.2 \times 10^{3}\right)^{*}$ \\
SU/D- & 11 & $1.2 \times 10^{7}$ \\
IOL+ & 26 & $2.1 \times 10^{5}\left(6.3 \times 10^{3}\right)^{*}$ \\
IOL- & 14 & s.
\end{tabular}

${ }^{*}$ Data after rejection extreme results for the strains W62 (group SU/D-) and $\mathrm{K} 48$ (group IOL-).

$>10^{6} \mathrm{cfu} 1$ square $\mathrm{cm}^{-1}$ of the skin and $>10^{7} \mathrm{cfu} 0.5 \mathrm{~g}^{-1}$ of internal organs (Table 5 and Figures 6 and $7(a)$ ). Similar level of adhesion to carp skin and trout liver was noted only for two strains (W62 and K48, resp.) which did not cause disease symptom in these tissues (Table 4 ). The remaining strains from the groups unable to cause external or internal lesions in particular fish species adhered poorly to skin or internal organs (Figure $7(\mathrm{~b})$ ). The means of cfu 1 square $\mathrm{cm}^{-1}$ of the skin or $0.5 \mathrm{~g}^{-1}$ of internal organs amounted to $4.2 \times$ $10^{3}$ or $6.3 \times 10^{3}$, respectively (Table 5 ). Numerous bacterial cells were visible on the slides covered with blood and exposed to the strains, which were able to cause septicaemia (Figure 8(a)) while the remaining strains adhered to blood cells very poorly (Figure 8(b)) and the majority of them were unnoticeable on the slides at all.

3.2.1. Statistical Analysis. The ratio of variances for the two group data was $F=0.2023, P$ value $=1.109 \mathrm{e}-06$, so these data were not consistent. Using U-Mann-Whitney-Wilcoxon's test, the results were $W=1352.5, P$ value $=5.222 \mathrm{e}-12$. Zero hypothesis (conformity of the data) was rejected on the basis $P$ value. Therefore, the difference between means of the two groups were statistically significant at $\alpha \leq 0.05$.

\section{Discussion}

Mesophilic aeromonads are a peculiar group of bacteria because of their large taxonomic and serological diversity and at the same time Aeromonas serogroups are not species specific [11, 20, 21]. According to Popoff's [22] classifications of the genus Aeromonas, A. hydrophila, A. caviae, and A. sobria have been reported as the species responsible for the most different conditions in fish. It is currently known that each of these species contains 3-5 hybridization groups, and at least 14 phenotypically described separate Aeromonas species are recognized [1]. This fact as well as serological diversity of motile aeromonads suggested the relationship may appear between specific disease symptoms and currently recognized species or/and serogroups. It has been, at some degree, shown for Aeromonas strains isolated from various human specimens $[2,21,23,24]$.

This is the first study on the determination of similar links in fish infections caused by motile aeromonads. It is very important problem because a Aeromonas spp. constitute very often the component of mixed bacterial flora isolated from asymptomatic carriers as well as from fish with various disease conditions caused sometimes by bacteria belonging to completely different taxa. In such cases the correct diagnosis is very difficult.

In this study, all carps and all trouts originated from the same populations and remained under identical conditions, suitable for particular fish species, during experiments. Furthermore, identical doses of each strain were used for challenge tests. All these factors gave good comparability and reliability of the results.

No relationship between Aeromonas spp. or SG and their ability to cause lesions on the carps skin was observed. All strains except one formed less or more extensive ulcers or dermatitis. However, skin ulcers in trout were only caused by the strains belonging to some Aeromonas species or/and serogroups. The presence of any lesions in internal organs with or without septicaemia syndrome in both carp and trout depended also markedly on taxonomic membership of the strains. At the same time, it is worth stressing that specific disease symptoms caused by strains belonging to all species except $A$. hydrophila varied also depending on fish species. All strains of $A$. veronii bt. sobria caused septicaemia only in carp. The species has also been described as the causative agent of septicaemia syndrome in spotted sand bas [17]. From 8 serogroups of $A$. salmonicida used to challenge, only strains belonging to SG O3 were able to cause 


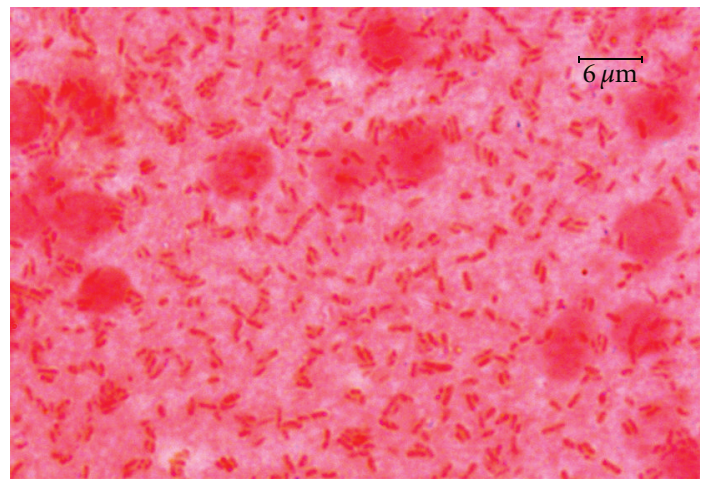

(a)

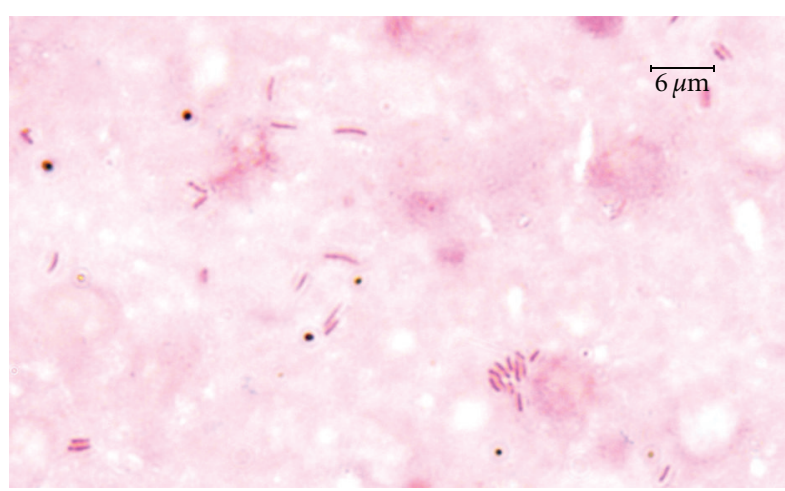

(b)

Figure 7: Numerous bacterial cells of A. hydrophila strain Pt104 (a) adhering to trout liver (a) and isolated bacterial cells of A. sobria strain K24 adhering to carp kidney (b).

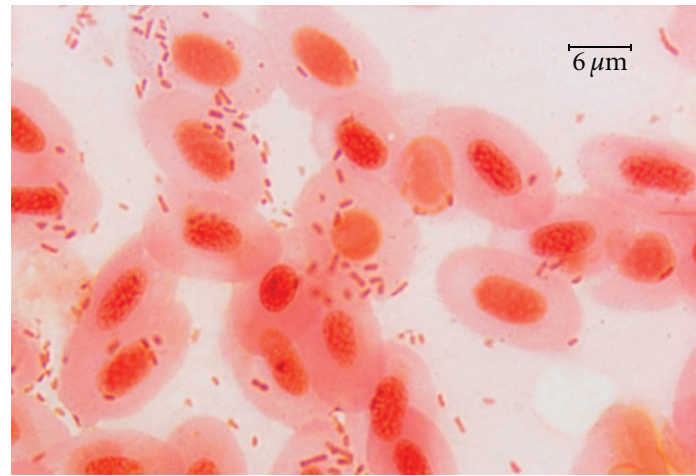

(a)

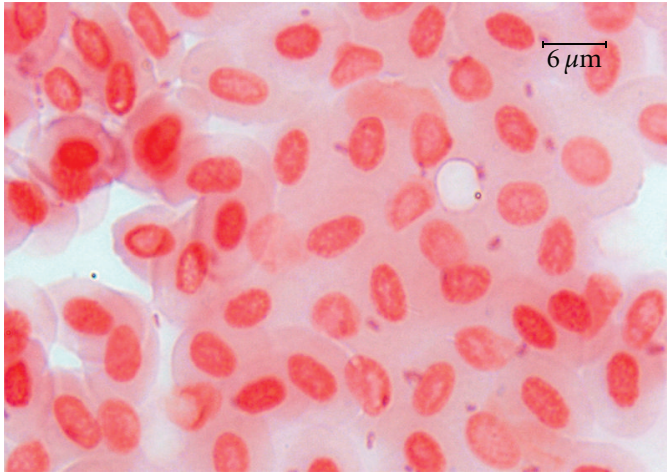

(b)

Figure 8: Numerous bacterial cells of A. hydrophila strain Pt 104 (a) and isolated cells of A. veronii bt. sobria strain W62 (b) adhering to trout blood cells.

systemic infection in carp. In contrast, septicaemia syndrome in trout was observed after challenge with all strains of A. salmonicida, and A. sobria. The latter species has been described as a causative agent of serious disease in perch [8]. No A. bestiarum strain was able to cause septicaemia symptoms although all caused relatively mild lesions in internal organs of trout. Only some strains (SGs O3 and O11) of the species caused similar lesions in carp and some others (SGs O16, PGO2 and PGO6) skin ulcers in trout. A. hydrophila was only one species able to cause ulcers as well as systemic infection in both carp and trout. This species has also been reported as one of Aeromonas spp. responsible for haemorrhaging septicaemia in eels [6]. It should be stressed that $A$. hydrophila and $A$. veronii bt. sobria, especially from SGs O11 and O16, are also predominant in human bloodborne infections and the latter species also in gastroenteritis $[2,21,24,25]$. It indicates that fish infected with these species may be hazardous for human health.

Pathogenicity of motile aeromonads is multifactorial, but adhesion and colonization of various host cells seem to be the most important factor for initiation of disease process [2, 26-28]. However, some investigators have found no correlation between virulence and adhesion ability of motile aeromonads [29]. All Aeromonas strains tested in this study were virulent for fish as has previously been showed [7, 11]. However, most of these strains, except $A$. hydrophila, caused disparate disease symptoms depending on Aeromonas species and/or serogroups. It may be associated with the kind of bacterial adhesins. Structures such as fimbria (pili), LPS, outer membranes (OmpA), and lectins have been reported as adhesins of Aeromonas spp. [17, 26, 3032]. Possibly, these adhesive factors are Aeromonas species specific. There has been shown that adhesion factors of $A$. veronii are cell-associated lectin MCBP or OmpA [17, 32], whereas structures such as pili, LPS and OmpII were reported as adhesins in A. hydrophila [26, 31, 33]. Various adhesin structures may explain the ability of the strains belonging to these species, especially $A$. hydrophila, to cause large spectrum, of disease in various fish species.

Bacterial adhesion processes involve also specific receptor structures on fish cells such as glycoproteins of intestinal gut mucus [28] or mucin, lactoferrin, and collagen [17]. Carbohydrate-rich substrates have also been suggested as receptors for Aeromonas adhesins [34]. Therefore, various models such as trout and carp skin and blood, carp kidney, 
and trout liver were used for adhesion tests in this study. It was found very good correlation between adhesion intensity to particular tissues and their susceptibility to infection. Adhesion intensity of particular Aeromonas strains to tissues susceptible to infection was significantly higher than to those which were not affected by them. This indicates that specific receptor structures for Aeromonas adhesins are different on the skin mucus, internal organs, and blood cells. They seem also to be fish species specific. This confirms the previous suggestions that fish skin mucus has host-specific properties [27].

Carp skin was susceptible to infection of all Aeromonas strains used to challenge and at the same time all strains tested for adhesion showed intensive adhesion ability to the tissue. Probably, in carp body surface mucus are located receptors specific for various adhesive factors of particular Aeromonas species and serogroups.

The results of this study indicate that the presence of Aeromonas bacteria in fish tissue samples is not necessarily a sign that they can cause disease or are causative agent of observed disorders. The presented findings provided evidence that even bacteria commonly known as pathogenic for fish are not able to cause pathological symptoms in some body sites if their adhesion is very poor to specific tissues. Therefore, isolation of such bacteria from mixed bacterial flora does not always indicate that they are primary factor of a disease. It should be stressed that Aeromonas bacteria overgrow often some other pathogenic microorganisms, for example, A. salmonicida ssp. salmonicida or Flavobacterium spp [5], which require longer time to grow. In such cases isolation of these bacteria is very difficult. As was shown in this study, Aeromonas strains unable to cause lesions adhered weakly to tissue and were easily removed from it by washing. This fact may be of use during preparation of fish tissue material. Our preliminary comparative studies showed that the washing of the skin, gills, and some internal organs (with tight consistency) markedly reduced Aeromonas cells and the proportion of these bacteria to other microorganisms markedly decreased. The picture of bacterial culture was then more clear and facilitated isolation of pathogens such as Aeromonas salmonicida ssp. salmonicida, Flavobacterium columnare, and Streptococcus spp. (data not published).

\section{Conclusions}

From the data presented in this paper, it is apparent that A. hydrophila is the most versatile and dangerous species among fish pathogens from the genus Aeromonas. Probably it is associated with the presence of various types of adhesins. Moreover, A. veronii bt. sobria was found as especially dangerous pathogen for carps and $A$. salmonicida and $A$. sobria for trouts. All these species are able to cause acute form of disease with septicaemia syndrome. There was found that disease symptoms caused by Aeromonas spp., except A. hydrophila, are specific for both bacteria and fish species to a considerable degree. There seems to be poor correlation between Aeromonas serogroups and the disease picture although it was found among the strains belonging to the species $A$. bestiarum, $A$. salmonicida, and $A$. veronii bt. sobria. There was evident correlation between adhesion intensity of the strains to specific fish tissues and disease spectrum caused by them. This indicates that adhesion to various cells of fish organism may be the principal marker to detect virulent Aeromonas strains, which may cause specific disease spectrum in carps or/and trouts.

The findings presented in this study, especially concerning different ability of particular Aeromonas species and some serogroups of these bacteria to cause specific lesions in carp and trout, may be helpful in an appraisal of aeromonad disease risk and the kind of the infection in particular fish farms by epizootiological studies or/and during routine fish examinations. Adhesion ability may facilitate and improve diagnosis of bacterial fish diseases. However, adhesion of Aeromonas spp. may be mediated by both specific and nonspecific charge and hydrophobic interactions [17]. Therefore, complementary studies are needed in order to better understand the type of adhesion process of particular Aeromonas species and serogroups to various fish tissues.

\section{References}

[1] A. M. Carnahan and S.W. Joseph, "Family I. Aeromonadaceae," in Bergey's Manual of Systematic Bacteriology, D. J. Brenner, N. R. Krieg, and J. T. Staley, Eds., vol. 2, Springer, New York, NY, USA, 2005.

[2] J. M. Janda and S. L. Abbott, "The genus Aeromonas: taxonomy, pathogenicity, and infection," Clinical Microbiology Reviews, vol. 23, no. 1, pp. 35-73, 2010.

[3] P. Monfort and B. Baleux, "Dynamics of Aeromonas hydrophila, Aeromonas sobria, and Aeromonas caviae in a sewage treatment pond," Applied and Environmental Microbiology, vol. 56, no. 7, pp. 1999-2006, 1990.

[4] L. Noterdaeme, S. Bigawa, K. A. Willams, and F. Ollevier, "Biochemical and physiological characteristics and plasmid profiles of Aeromonas hydrophila strains isolated from freshwater fish and from fresh water," Journal of Fish Diseases, vol. 14, no. 3, pp. 313-321, 1991.

[5] B. Austin and D. A. Austin, Bacterial Fish Pathogens. Disease of Farmed and Wild Fish, Praxis Publishing Ltd., Chichester, UK, 2007.

[6] C. Esteve, C. Amaro, E. Garay, Y. Santos, and A. E. Toranzo, "Pathogenicity of live bacteria and extracellular products of motile Aeromonas isolated from eels," Journal of Applied Bacteriology, vol. 78, no. 5, pp. 555-562, 1995.

[7] A. Kozińska, "Dominant pathogenic species of mesophilic aeromonads isolated from diseased and healthy fish cultured in Poland," Journal of Fish Diseases, vol. 30, no. 5, pp. 293-301, 2007.

[8] T. Wahli, S. E. Burr, D. Pugovkin, O. Mueller, and J. Frey, "Aeromonas sobria, a causative agent of disease in farmed perch, Perca fluviatilis L," Journal of Fish Diseases, vol. 28, no. 3, pp. 141-150, 2005.

[9] R. Sakazaki and T. Shimada, "O-serogrouping scheme for mesophilic Aeromonas strains," Japanese Journal of Medical Science and Biology, vol. 37, no. 5-6, pp. 247-255, 1984.

[10] C. Esteve, E. Alcaide, R. Canals et al., "Pathogenic Aeromonas hydrophila serogroup O:14 and O:81 strains with an S layer," Applied and Environmental Microbiology, vol. 70, no. 10, pp. 5898-5904, 2004. 
[11] A. Kozińska and A. Pekala, "Serotyping of Aeromonas species isolated from Polish fish farms in relation to species and virulence phenotype of the bacteria," Bulletin of the Veterinary Institute in Pulawy, vol. 54, no. 3, pp. 315-320, 2010.

[12] Y. Santos, I. Bandin, and A. E. Toranzo, "Immunological analysis of extracellular products and cell surface components of motile Aeromonas isolated from fish," Journal of Applied Bacteriology, vol. 81, no. 6, pp. 585-593, 1996.

[13] A. C. Camus, R. M. Durborow, W. G. Hemstreet, R. L. Thune, and J. P. Hawke, Aeromonas Bacterial InfectionsMotile Aeromonad Septicemia, SRAC-Publications, 1998.

[14] R. C. Cipriano, "Aeromonas hydrophila and motile aeromonad septicemias of fish," Fish Disease Leaflet 68, 2001, http://www.lsc.usgs.gov/.

[15] T. Majumdar, S. Ghosh, J. Pal, and S. Mazumder, "Possible role of a plasmid in the pathogenesis of a fish disease caused by Aeromonas hydrophila," Aquaculture, vol. 256, no. 1-4, pp. 95104, 2006.

[16] W. O. Ogara, P. G. Mbuthia, H. F. A. Kaburia et al., "Motile aeromonads associated with rainbow trout (Onchoryncus mykiss) mortality in Kenya," Bulletin of the European Association of Fish Pathologists, vol. 18, no. 1, pp. 7-9, 1998.

[17] M. A. Guzman-Murillo, M. L. Merino-Contreras, and F. Ascencio, "Interaction between Aeromonas veronii and epithelial cells of spotted sand bass (Paralabrax maculatofasciatus) in culture," Journal of Applied Microbiology, vol. 88, no. 5, pp. 897-906, 2000.

[18] M. Rahman, P. Colque-Navarro, I. Kühn, G. Huys, J. Swings, and R. Möllby, "Identification and characterization of pathogenic Aeromonas veronii biovar sobria associated with epizootic ulcerative syndrome in fish in Bangladesh," Applied and Environmental Microbiology, vol. 68, no. 2, pp. 650-655, 2002.

[19] T. C. Hsu, W. D. Waltman, and E. B. Shotts, "Correlation of extracellular enzymatic activity and biochemical characteristics with regard to virulence of Aeromonas hydrophila," Developments in Biological Standarization, vol. 49, pp. 101$111,1981$.

[20] S. V. Alavandi and S. Ananthan, "Biochemical characteristics, serogroups, and virulence factors of Aeromonas species isolated from cases of diarrhoea and domestic water samples in Chennai," Indian Journal of Medical Microbiology, vol. 21, no. 4, pp. 233-238, 2003.

[21] J. M. Janda, S. L. Abbott, S. Khashe, G. H. Kellogg, and T. Shimada, "Further studies on biochemical characteristics and serologic properties of the genus Aeromonas," Journal of Clinical Microbiology, vol. 34, no. 8, pp. 1930-1933, 1996.

[22] M. Popoff, "Genus III Aeromonas", in Bergey's Manual of Systematic Bacteriology, N. R. Krieg and J. G. Holt, Eds., vol. 1, Williams \& Wilkins, Baltimore, Md, USA, 1984.

[23] N. Borrell, M. J. Figueras, and J. Guarro, "Phenotypic identification of Aeromonas genomospecies from clinical and environmental sources," Canadian Journal of Microbiology, vol. 44, no. 2, pp. 103-108, 1998.

[24] R. N. Thomsen and M. M. Kristiansen, "Three cases of bacteraemia caused by Aeromonas veronii biovar sobria," Scandinavian Journal of Infectious Diseases, vol. 33, no. 9, pp. 718-719, 2001.

[25] J. Vila, J. Ruiz, F. Gallardo et al., "Aeromonas spp. and traveler's diarrhea: clinical features and antimicrobial resistance," Emerging Infectious Diseases, vol. 9, no. 5, pp. 552-555, 2003.

[26] A. Kozinska, Pathogenicity markers of Aeromonas hydrophila, Aeromonas caviae and Aeromonas sobria, Ph.D. thesis, National Veterinary Research Institute, Pulawy, Poland, 1996.
[27] K. Krovacek, Studies on putative virulence factors in Aeromonas hydrophilic and Vibrio anguillarum from fish and aquatic environments, thesis, Swedish University of Agricultural Sciences, Faculty of Veterinary Medicine, Uppsala, Sweden, 1989.

[28] M. van der Marel, V. Schroers, H. Neuhaus, and D. Steinhagen, "Chemotaxis towards, adhesion to, and growth in carp gut mucus of two Aeromonas hydrophila strains with different pathogenicity for common carp, Cyprinus carpio L," Journal of Fish Diseases, vol. 31, no. 5, pp. 321-330, 2008.

[29] F. del Corral, E. B. Shotts Jr., and J. Brown, "Adherence, haemagglutination and cell surface characteristics of motile aeromonads virulent for fish," Journal of Fish Diseases, vol. 13, no. 4, pp. 255-268, 1990.

[30] R. Lallier and P. Daigneault, "Antigenic differentiation of pili from non-virulent and fish-pathogenic strains of Aeromonas hydrophila," Journal of Fish Diseases, vol. 7, no. 6, pp. 509-512, 1984.

[31] S. Merino, X. Rubires, A. Aguilar, and J. M. Tomás, "The O:34-antigen lipopolysaccharide as an adhesin in Aeromonas hydrophila," FEMS Microbiology Letters, vol. 139, no. 2-3, pp. 97-101, 1996.

[32] A. Namba, N. Mano, H. Takano, T. Beppu, K. Ueda, and H. Hirose, "OmpA is an adhesion factor of Aeromonas veronii, an optimistic pathogen that habituates in carp intestinal tract," Journal of Applied Microbiology, vol. 105, no. 5, pp. 1441-1451, 2008.

[33] S. Y. Lee, Z. Yin, R. Ge, and Y. M. Sin, "Isolation and characterization of fish Aeromonas hydrophila adhesins important for in vitro epithelial cell invasion," Journal of Fish Diseases, vol. 20, no. 3, pp. 169-175, 1997.

[34] C. M. Rocha-de-Souza, R. Hirata Jr., A. L. Mattos-Guaraldi, A. C. Freitas-Almeida, and A. F. B. Andrade, "Lectin-binding properties of Aeromonas caviae strains," Brazilian Journal of Microbiology, vol. 39, no. 2, pp. 214-218, 2008. 

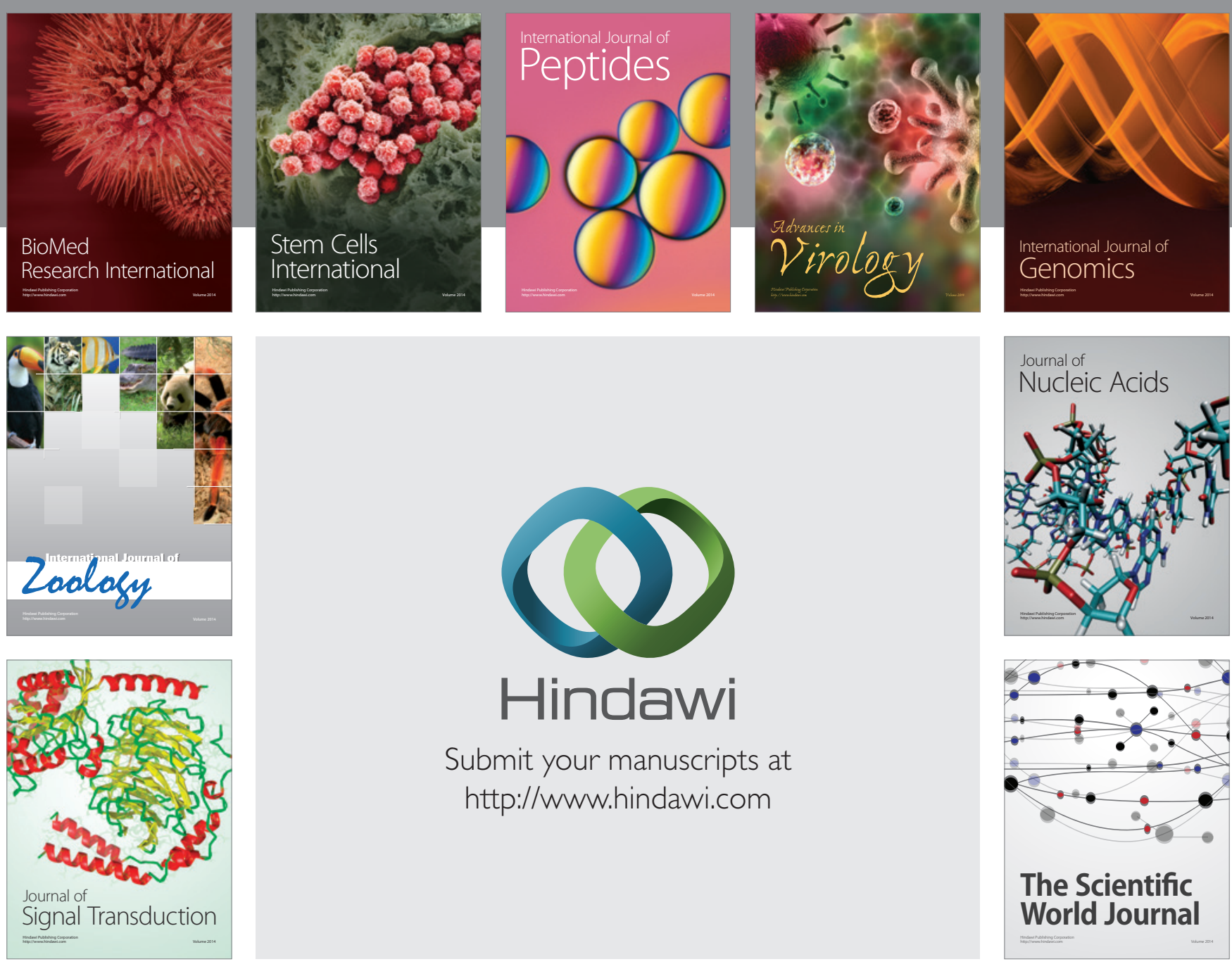

Submit your manuscripts at

http://www.hindawi.com
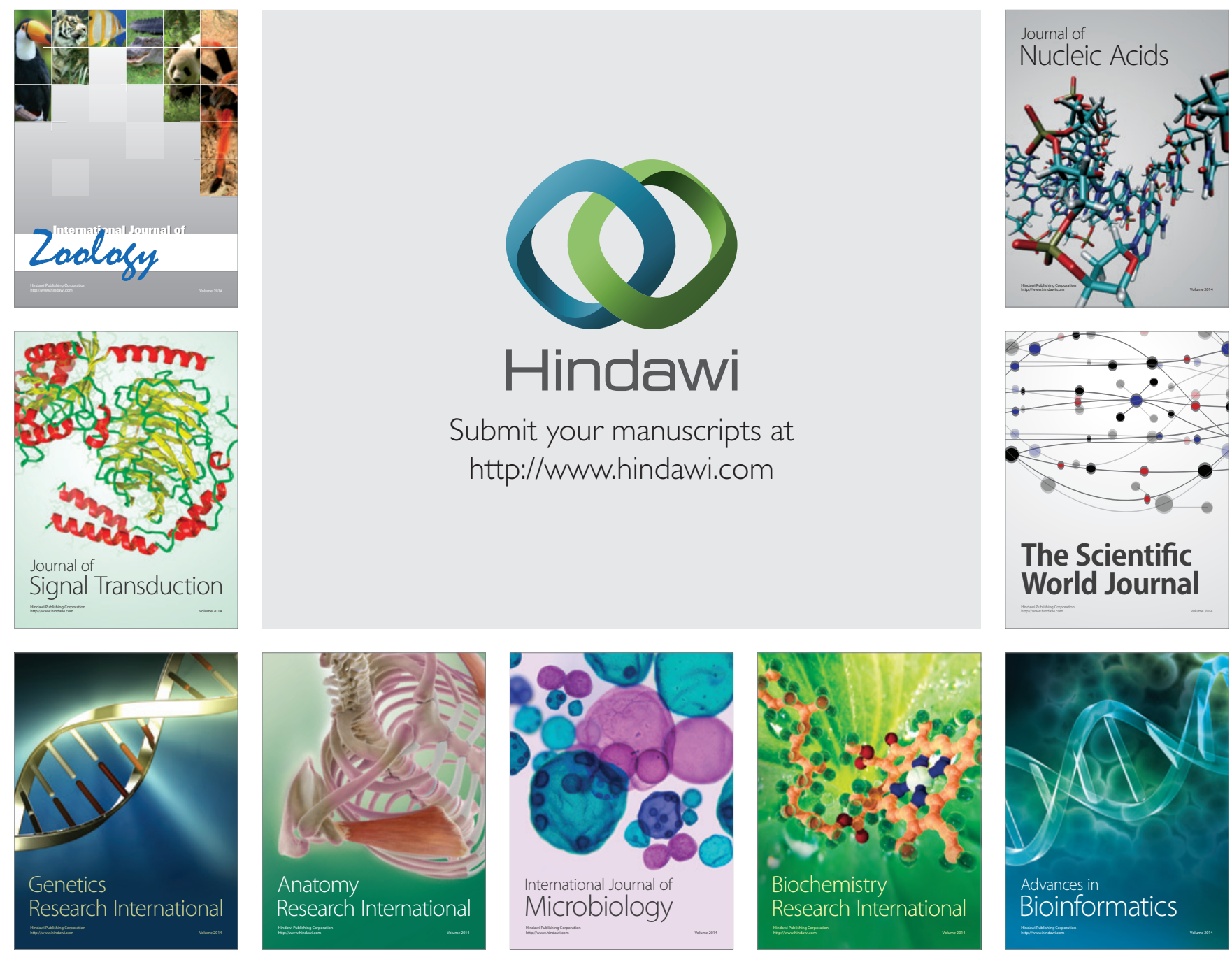

The Scientific World Journal
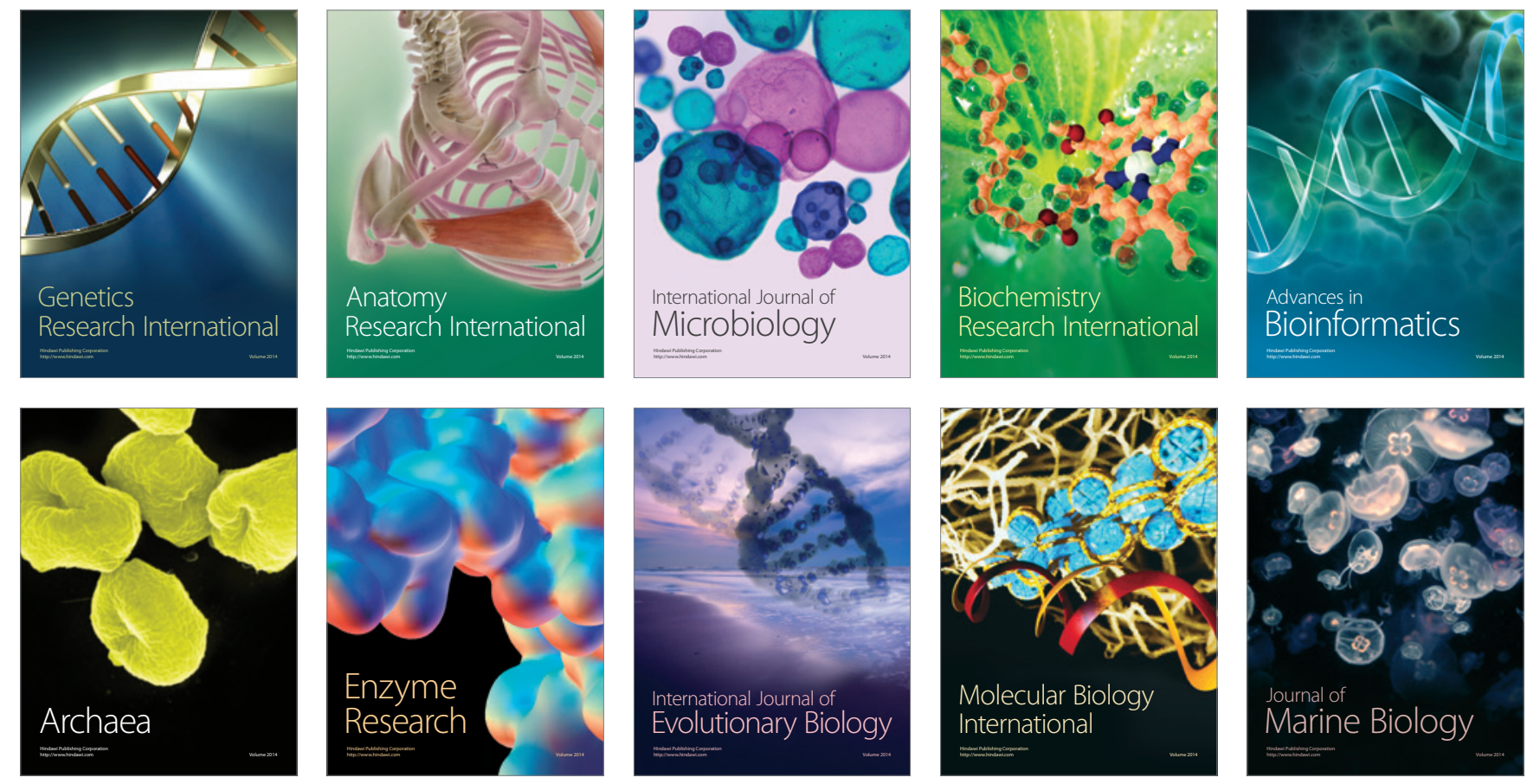